\title{
Use of Scientific Language by University Physics Students Communicating to the Public
}

\author{
Kathleen Hinko ${ }^{1,2}$, Jordan Seneca ${ }^{1}$ and Noah Finkelstein ${ }^{1}$ \\ Department of Physics ${ }^{1}$ and JILA NSF Physics Frontier Center for Atomic, Molecular and Optical Physics², \\ University of Colorado Boulder, CO 80309, USA
}

\begin{abstract}
Communicating to non-expert audiences about advanced physics topics and current research is an essential practice for physicists. Typical language used by physicists speaking to other physicists, however, draws on a wealth of prior knowledge and community norms; using such scientific language with public audiences can be a barrier to effective communication. Drawing from observations and literature, we present a framework for the assessment of scientific language of physics students communicating scientific meaning to non-expert audiences. We apply this framework to the analysis of videos of university physics students instructed to describe their research to children. We classify the types of scientific language used by students and identify strategies they employ to mitigate the impact of jargon on the audience.
\end{abstract}

Keywords: Physics education research, informal science education, science communication PACS: 01.40.Fk, 01.40.-d

\section{INTRODUCTION}

It is vital for both physicists and physics students to be able to communicate about scientific ideas, questions and research to various audiences. Publishing papers, giving presentations, collaborating with others, and writing grants are necessary communication practices for faculty and individuals in industry positions, as well as for some physics students. In these cases, the communication is with individuals with expertise in the field. As part of their scientific practice, however, physicists are often required to communicate their findings to broader audiences who are not experts in science. Physicists may seek connections with public audiences to promote scientific literacy and interest, as well as to satisfy broader impact requirements on grants [1]. They may communicate to diverse communities through public lectures and outreach programs. For non-expert audiences, effective communication is critical; failure can result in less support for science funding and a fundamental mistrust of scientists [2].

As communicating to general audiences is a nontrivial activity for scientists, some institutional entities have recognized the need to train both professionals and students to this end. The American Physical Society recommends that proficiency in science communication be treated as an object of undergraduate and graduate education - an outcome to be achieved along with knowledge of physics content and other practices [3]. The AAAS [4] and the Alan Alda Center for Communicating Science at Stony Brook University [5] facilitate instructional programs and communication workshops for scientists and engineers. For students, there are some university programs in science communication, but these are either separate certificate programs or housed in other departments such as communication or journalism [for example: 6,7$]$. Physics programs typically do not have explicit curricular elements that support public communication; they may have at most a single class [8] or voluntary participation in outreach programs [9]. Since physicists are called upon to communicate to the public, this topic is relevant to the professional development of physics students.

In this work, we examine communication practices of university physics students when they are addressing a non-expert audience. We develop a framework for scientific language use by physicists for a public context. Then we apply this framework to the analysis of university students' verbal communication about their physics research to children.

\section{COMMUNICATION FRAMEWORK}

Physicists communicate about scientific content constantly to various groups. For instance, during a typical day, a physics professor may meet with students in her research group, teach an undergraduate class, write a grant proposal or journal article, engage in scientific discussions with colleagues, attend colloquium, and speak with family members about her day at dinner. In each of these cases, the physicist communicates to another person or group who may or may not have similar levels of expertise in the same sub-field of physics. Similar communication experiences are typical for university physics students. Figure 1 shows a range of audiences with which a graduate student may communicate about physics.

The content of scientific communication varies with each audience. Physicists may have the most experience and training in communicating their scientific progress and outcomes to other experts in 
their sub-field. In these cases, using science-specific language, or jargon, without explanation is likely appropriate since they are writing and speaking with others who are working on similar scientific research. Ochs et al. has studied jargon use and documented the existence of particular communication norms (such as switching between first and third person to describe behavior of physical entities) that permit a type of shorthand between physicists working in research groups [10]. Physicists also use certain language when communicating with scientists from other disciplines, who are versed in scientific practice and common language of the broader field.

FIGURE 1. Physicists and physics students communicate about science with a variety of different groups.

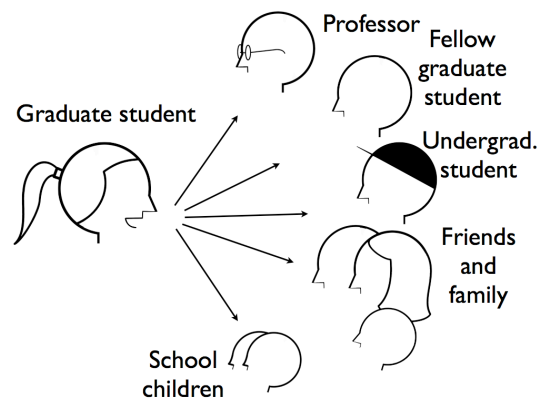

There are, however, many instances where physicists speak to non-experts about various issues related to science, including current research topics. In these cases, using the same strategies and levels of scientific jargon as with fellow physicists may not be appropriate, and is discouraged [13]. Researchers have been studying jargon and strategies used by scientists when communicating to different groups. Sevian and Gonsalves have analyzed student speeches on research for pedagogical content knowledge and overall presentation style [11]. Kapon et al. have identified 4 elements of language (analogies, narrative elements, organization, and content choices) that are used in popular public lectures by physics professors [12]. Additionally, Sharon and Baram-Tsabari have quantified jargon by comparing language used in academic seminars and TED Talks to databases of common science and everyday words [13]. We draw from this body of literature as the basis for our analysis of scientific communication by physics students to K-8 children in an afterschool program. We focus in this work, however, on language that is specific to the physics content - scientific jargon use in context (instead of compared to non-contextual databases) - and exclude analysis of best practices for general verbal communication (eye contact, vocal tone).

\section{STUDY METHODS}

Here, we characterize scientific language use by graduate and undergraduate students who choose to participate in a physics outreach program for children. In the Partnerships for Informal Science Education in the Community (PISEC) program [14], university educators (UEs) work on hands-on physics activities with children during weekly afterschool sessions. One UE typically works with a small group of 2-4 children for 8-10 weeks during a semester. In this mentoring role, UEs communicate directly with children and receive immediate feedback from them.

After signing up to participate in PISEC, UEs are asked to make communication study video using an instrument that consists of two prompts. The first prompt asks students to explain a short paragraph from a textbook on the topic of velocity. The second prompt asks students to "Describe your research." They are asked to imagine an audience of PISEC children $\left(4^{\text {th }}-8^{\text {th }}\right.$ graders, from underrepresented groups, with limited access to physics research or contact with physicists). Subjects are given a few minutes preparation, and then recorded responding to these prompts in an empty room (with no actual audience). The videos are typically five minutes in length. Some students recorded another video with the same prompts at the end of their first semester of participation.

We have collected 12 total UE communication videos: 9 pre-videos and 3 matching post-videos. These data have been collected over the course of several years due to the small size of the PISEC program. In this work, we focus on the second prompt (results from the first prompt are described in [15]). Videos were viewed and transcribed. An emergent coding scheme was developed, and the transcripts were coded accordingly.

\section{SCIENTIFIC LANGUAGE ANALYSIS}

In our study, we have identified two types of scientific jargon UEs use to describe their physics research and four types of strategies that UEs employ to explain scientific jargon. Table 1 lists and describes each category. While not exhaustive, these categories represent our findings of the scientific language used. These categories are specific to our data set, and further work is required to be generalizable. In contrast to previously mentioned studies on jargon use, we code by considering occurrences of scientific language in the context of the rest of the response to the prompt as well as situate the codes within the physics lexicon. 
TABLE 1. Codes for scientific language use and strategies.

\begin{tabular}{|c|l|}
\hline $\begin{array}{c}\text { Use of Scientific } \\
\text { Jargon }\end{array}$ & \multicolumn{1}{c|}{ Description } \\
\hline $\begin{array}{c}\text { Discipline- } \\
\text { specific Science } \\
\text { Phrase }\end{array}$ & $\begin{array}{l}\text { A word or phrase that is used to } \\
\text { communicate a discipline-specific } \\
\text { science concept. Level can vary by } \\
\text { amount of prior knowledge that is } \\
\text { embedded in the phrase. Specific to the } \\
\text { physics discipline in this study. }\end{array}$ \\
\hline $\begin{array}{c}\text { Hybrid Science } \\
\text { Phrase }\end{array}$ & $\begin{array}{l}\text { A word or phrase that is used to } \\
\text { communicate a scientific concept but } \\
\text { that does not only have a discipline- } \\
\text { specific science meaning. }\end{array}$ \\
\hline $\begin{array}{c}\text { Strategies to } \\
\text { Convey Meaning }\end{array}$ & $\begin{array}{l}\text { Speaker draws a parallel to another, } \\
\text { potentially more familiar concept to } \\
\text { explain the scientific concept. }\end{array}$ \\
\hline Analogy & $\begin{array}{l}\text { Speaker gives several examples to } \\
\text { illustrate a concept. }\end{array}$ \\
\hline Illustration & $\begin{array}{l}\text { Attempt by the speaker to define a } \\
\text { jargon word he/she has used. }\end{array}$ \\
\hline Explanation \\
\hline Colloquialism & $\begin{array}{l}\text { A simplification of a scientific concept } \\
\text { in everyday language that does not have } \\
\text { a precise scientific meaning. }\end{array}$ \\
\hline
\end{tabular}

\section{Use of Scientific Language}

Scientific language is used by UEs in two main ways: with discipline-specific science words or phrases and through hybrid science words or phrases.

Discipline-specific science phrases are terms that are used in physics and carry scientific meaning, which is why they are convenient to use when communicating with other physicists about research. However, varying levels of prior content knowledge are necessary to fully understand the scientific meaning of the phrase. We find that UEs often use physics-specific phrases when introducing their research topic, or in the middle of their research descriptions, when they are employing a strategy to explain jargon and end up introducing other jargon words in the process. Examples include:

"In our lab we are currently looking at BoseEinstein condensate in two dimensions [...]”

\section{"[...] that can only be described by the laws of quantum mechanics."}

"We're understanding how molecules interact with each other $[\ldots]$ "

Discipline-specific science phrases can be characterized by the academic level at which one would be introduced to this term or terms. While state science education standards and personal experiences vary, we find delineations between (L1) grade school, (L2) high school/ introductory undergraduate, and (L3) upper level undergraduate/ graduate levels of physics jargon. For instance, in the above examples, "molecules" would be classified as Ll, and "BoseEinstein condensate" as L3. We find that in the prevideos, when they were asked to communicate with 4- $8^{\text {th }}$ graders, all 9 UEs used a L2 discipline-specific phrase and 6 UEs further used L3 phrases.

Hybrid science phrases are the use of words or phrases that can have both scientific meaning but also meaning in everyday life. Included in this category are instances of UEs using the everyday meaning of a word and also instances of UEs using a word that is often used in scientific contexts, but they are using it casually, not as part of a definition in their research descriptions. Examples include:

"And so that's kind of what I do, except on much smaller scales $[\ldots]$ "..]

"Let's say I take light and I shine it on some matter and something happens, we get some response."

This category of scientific language is complex and potentially high impact - communication to the public may be impeded in subtle but crucial ways by physicists "accidental" use of scientific terms or of everyday terms that may have nontrivial scientific meaning. We plan to unpack the significance of this category in future work - we will focus in the rest of this paper on the strategies that UEs use with regard to discipline-specific science phrases.

\section{Strategies to Convey Scientific Meaning}

In some videos, UEs recognized their use of discipline-specific science words or phrases. They would then verbally acknowledge the phrase as being complicated or direct the focus from the actual terminology. We find that they often followed with certain strategies and used alternative language to convey the scientific meaning behind the phrase. We have classified four main types of strategies used by UEs to convey scientific meaning: analogies, illustrations, explanations and colloquialisms. Each category is described below with corresponding examples from video transcripts.

Analogy: Students draw parallels between their research and a situation they perceive to be familiar to the audience, referring to similarities in order to give a picture of a complex scientific construct. Sometimes the analogy relates to a single concept, and other times it is used as a framing device for their entire research description. This strategy may be sophisticated in comparison to other strategies and was only used by a few UEs. An example from our data is: 
"We're understanding how molecules interact with each other, by blowing them up with a laser and figuring out how they were originally in the first place. [...] like if we were bowling and trying to put the pins back based on where they fell in the first place."

Illustration: Students clarify a discipline-specific science word by giving one or several examples of familiar scenarios that can be compared in terms of scope or scale. Illustrative phrases differ from analogies in that they are direct comparisons and share the same properties of the original phrase - for instance, describing how cold something is by listing other cold objects. This strategy was used frequently by UEs. Examples include:

"By tiny I mean much smaller than not even a human hair, but less than a thousandth of a human hair, or even smaller."

"[...] if you were to take ten Antarcticas, put them all together, and put them into your freezer, you wouldn't even be even close to this cold as we go."

Explanation: Students attempt to provide a description of the characteristics or mechanisms of a disciplinespecific concept. The explanation is often given as a definition of the word or phrase. Explanations differ from analogies and illustrations in that they are not explicitly comparative. This strategy was used frequently by UEs. Examples include:

" a vacuum is essentially a place that has no air"

"I take molecules, which are just small (...) groups of atoms put together"

Colloquialism: Students employ informal language to describe a discipline-specific science phrase in place of more precise terminology. Verbs or adjectives that are familiar to the audience are used instead. This strategy was continually used by UEs; it may also be used between physics researchers as documented by Ochs [10]. Examples from UEs are:

" [...] that's really just a big word for saying we shoot lasers at things and see what happens."

"[...] those atoms are going to wiggle around inside that material."

\section{DISCUSSION}

All UEs used technical scientific words and phrases, even when prompted to address school children. We find a frequent use of hybrid science phrases, which may be confusing to audiences due to their homonymy. There may be several reasons that UEs use jargon with a general audience. The UEs might be accustomed to speaking with other physics students and professors and are unaware of their jargon use. They may misjudge the background and academic level of their audience. They may also realize they are using jargon but are not equipped with alternative language, may not understand the term well enough to describe it differently, or are reluctant to deviate from the precise physics meaning of the term. Jargon use, however, is not necessarily an impediment to public understanding if strategies to circumvent audience alienation are employed effectively by scientists. We find that UEs employ several types of communication strategies to mitigate the negative impact of their jargon use: analogies, illustrations and explanations as well as colloquialisms.

Future work will include coding additional UE videos for discipline-specific and hybrid science phrases, determining the frequency of use of particular strategies, and comparing pre- and post-videos for individual UEs. By increasing our understanding of the communication practices of physics students, we will be able to design appropriate professional development opportunities and advocate for their participation in programs that support best communication practices, including outreach.

\section{ACKNOWLEDGMENTS}

We thank the JILA NSF Physics Frontier Center and the PER group at CU Boulder. This work is funded by NSF Grants \#1548494 and \#0833364.

\section{REFERENCES}

[1] http://www.nsf.gov/pubs/2002/nsf022/bicexamples.pdf

[2] J. R. Weber and C. S. Word, Biosci. 51487 (2001).

[3] APS Conference Report, "Graduate Education in Physics: Which Way Forward?” College Park,MD, 2008.

[4] AAAS Science Communication, http://www.aaas.org/ page/communicating-science-workshops

[5] Alan Alda Center for Communicating Science at Stony Brook, http://www.centerforcommunicatingscience.org

[6] University of California Santa Cruz, Science Communication, http://scicom.ucsc.edu/index.html

[7] Boston Univ., Sci. Journalism, http://www.bu.edu/com/ academics/journalism/graduate/science-journalism/

[8] Such as the Florida State University course, Communication in Physics.

[9] K. Hinko and N. Finkelstein, proc. PERC, AIP, 2012.

[10] Ochs et al. Interactions and Grammar, Ch. 7, Cambridge University Press, 1996.

[11] H. Sevian \& L. Gonsalves, Int. J. Sci. Ed., 30:11, 1441-1467 (2008).

[12] S. Kapon, U. Ganiel \& B. S. Eylon, Int. J. Sci. Ed., 32:2, 245-264 (2010).

[13] A. Sharon \& A. Baram-Tsabari. Pub. Und. Sci. (2013).

[14] PISEC, http://www.colorado.edu/physics/PISEC

[15] L. Mayhew \& N. Finkelstein, proc. PERC, AIP, 2009. 